\title{
Anti-tumor effect of luteolin is accompanied by AMP-activated protein kinase and nuclear factor-kB modulation in HepG2 hepatocarcinoma cells
}

\author{
JIN-TAEK HWANG ${ }^{1}$, OCK JIN PARK ${ }^{2}$, YUN KYUNG LEE ${ }^{2}$, MI JEONG SUNG ${ }^{1}$, \\ HAENG JEON HUR ${ }^{1}$, MYUNG SUNNY KIM ${ }^{1}$, JOO HUN HA ${ }^{3}$ and DAE YOUNG KWON ${ }^{1}$ \\ ${ }^{1}$ Biogeron Research Group, Korea Food Research Institute, Bundanggu, Kyungki-do 463-746; \\ ${ }^{2}$ Department of Food and Nutrition, Hannam University Daedeok Valley Campus, Yuseong-gu, Daejeon 305-811; \\ ${ }^{3}$ Department of Biochemistry and Molecular Biology, Medical Research Center for Bioreaction to Reactive Oxygen \\ Species, Kyung Hee University School of Medicine, Tongdaemun-gu, Seoul 130-701, Republic of Korea
}

Received November 5, 2010; Accepted February 8, 2011

DOI: $10.3892 / \mathrm{ijmm} .2011 .667$

\begin{abstract}
Luteolin, a plant-derived flavonoid, is thought to inhibit tumor growth. However, the precise molecular mechanisms by which luteolin inhibits cancer cell growth remain unclear. In the present study, we evaluated the role of AMP-activated protein kinase (AMPK) in the inhibition of cancer cell growth by luteolin in HepG2 hepatocarcinoma cells. AMPK is a metabolic sensor and may prevent carcinogenesis via modulation of signaling networks. We found that luteolin strongly induced cell death in HepG2 cells and dramatically reduced the tumor volume in a tumor xenograft model; both effects were accompanied by AMPK activation by luteolin. Luteolin also had a strong inhibitory effect on nuclear factor (NF) $-\kappa \mathrm{B}$. To determine the relationship between AMPK and NF- $\mathrm{B}$ signaling, we used Compound $\mathrm{C}$, a pharmacological AMPK inhibitor, and a dominant-negative form of AMPK. Our results indicated that inhibition of AMPK activity restored luteolin-inhibited NF- $\mathrm{B}$ DNA-binding activity. These results suggest that AMPK activity is critical for the inhibition of cancer cell growth, possibly via modulation of $\mathrm{NF}-\kappa \mathrm{B}$ activity. We also showed that luteolin treatment causes the release of reactive oxygen species (ROS) and that these intracellular ROS in turn mediate AMPK-NF- $\kappa$ B signaling in HepG2 hepatocarcinoma cells. In conclusion, we propose that AMPK is a novel regulator of NF- $\kappa \mathrm{B}$ in luteolininduced cancer cell death. Furthermore, our results suggest that AMPK is an attractive target for cancer prevention by flavonoids.
\end{abstract}

Correspondence to: Dr Dae Young Kwon, Department of Functional Food Research, Korea Food Research Institute, 516 Baekhyundong, Bundanggu, Kyungki-do 463-746, Republic of Korea

E-mail: dykwon@kfri.re.kr

Key words: luteolin, AMP-activated protein kinase, nuclear factor- $\kappa \mathrm{B}$, reactive oxygen species, hepatocarcinoma cells

\section{Introduction}

A number of food-derived compounds are thought to prevent various diseases such as diabetes, obesity, cardiovascular disorders and even cancers $(1,2)$. The results of several recent studies suggest that regular consumption of vegetables and fruits can reduce the risk of hepatocellular carcinoma via the modulation of specific proteins $(2,3)$. In addition to food-derived compounds, plant-derived flavonoids are also thought to prevent a variety of diseases (2-4). Luteolin-rich herbal extracts have been used to prevent various diseases in Oriental countries. Luteolin is a flavonoid found in plant leaves, rinds, barks, clover and foods such as celery, green pepper and chamomile tea (5). The results of previous studies suggest that luteolin is beneficial in the prevention of tumor progression and reduces inflammatory responses via the modulation of intracellular signaling pathways $(6,7)$. The precise mechanism of luteolin-mediated cancer prevention is still unclear, although several critical mechanistic steps have been identified.

Prior research involving certain types of cancer cells has revealed abnormally increased expression or activity of nuclear factor (NF)- $\kappa \mathrm{B}$ in these cells, contributing to cancer growth, invasion, metastasis and malignancy $(8,9)$. NF- $\kappa \mathrm{B}$ is a transcription factor that mediates the immune response to infection. It is also involved in cellular responses stimulated by stress, cytokines and free radicals $(10,11)$. On activation, the inhibitor of $\kappa \mathrm{B}(\mathrm{I} \kappa \mathrm{B})$ protein is phosphorylated and dissociates from $N F-\kappa B$, which then translocates to the nucleus and binds to response elements (8-12). The DNA/NF- $\kappa \mathrm{B}$ complex stimulates the expression of target genes involved in inflammation, carcinogenesis and metastasis (8-12). Inhibition of $\mathrm{NF}-\kappa \mathrm{B}$ signaling by food-derived compounds may therefore provide a reasonable strategy for preventing cancer development.

AMP-activated protein kinase (AMPK) is an energysensing protein that plays a beneficial role in metabolic disorders and cancers (13). Recently, AMPK activation by food-derived compounds has been the focus of cancer 
prevention research (13-15). The results of a previous study suggest that epigallocatechin 3-gallate (EGCG), a flavonoid isolated from green tea, effectively inhibits cancer development by activating AMPK signaling (15). AMPK has also been reported to regulate the expression of p53, Akt and cyclooxygenase-2, thereby inhibiting cell proliferation and survival and inducing apoptosis $(16,17)$. These studies provide evidence that AMPK signaling may be linked to cancer development or prevention.

In the present study, we investigated whether AMPK inhibits $\mathrm{NF}-\kappa \mathrm{B}$ activity to induce hepatocarcinoma cell death. We found that AMPK activation by luteolin is necessary for the inhibition of NF- $\kappa$ B DNA-binding activity, a process mediated by the release of reactive oxygen species (ROS).

\section{Materials and methods}

Cell culture and reagents. HepG2 hepatoma cells were purchased from the American Type Culture Collection (ATCC) (Manassas, VA). The cells were cultured in Roswell Park Memorial Institute (RPMI)-1640 medium containing $10 \%$ fetal bovine serum. The phospho-specific acetyl-CoA carboxylase (ACC), AMPK, NF- $\mathrm{B}$, and $\beta$-actin antibodies were purchased from Cell Signaling Technology (Danvers, MA). We purchased (4,5-dimethylthiazol-2yl)-2,5-diphenyl2H-tetrazolium bromide (MTT), Hoechst 33342, propidium iodide (PI), N-acetylcysteine (NAC), and 2',7'-dichlorofluorescein diacetate (DCFH) from Sigma (St. Louis, MO). Luteolin was purchased from Alexis Biochemicals (San Diego, CA) and dissolved in dimethyl sulfoxide (DMSO).

Adenovirus-mediated gene expression. AMPK wild-type (WT) and AMPK dominant-negative (DN) forms were generated and transfected into cells, as described previously (18). Briefly, the cells were infected with the adenovirus expressing c-myc-tagged AMPK WT or AMPK DN construct overnight in normal medium conditions. After infection, gene expression was detected by Western blotting with a c-myc antibody.

Determination of cell proliferation. The cells were seeded in 24-well plates with luteolin for $48 \mathrm{~h}$ and then incubated with $30 \mu \mathrm{l}$ MTT solution [5 $\mathrm{mg} / \mathrm{ml}$ in phosphate-buffered saline (PBS)] for $2 \mathrm{~h}$ at $37^{\circ} \mathrm{C}$. After discarding the medium, the cells were directly exposed to DMSO, and the purple supernatants were transferred from the 24-well plate to a 96-well plate. Relative cell viability was determined with an enzyme-linked immunosorbent assay (ELISA) reader.

Electrophoretic mobility shift assay. An electrophoretic mobility shift assay (EMSA) for NF- $\mathrm{KB}$ was performed as described previously (19). DNA-binding signals were detected by chemiluminescent imaging, performed according to the manufacturer's instructions (EMSA Gel-Shift kit; Panomics, Redwood City, CA).

$N F-\kappa B$ activity assay. NF- $\kappa \mathrm{B}$ activity was measured using an enzyme-linked assay kit (Assay Design Inc., Ann Arbor, $\mathrm{MI})$, according to the manufacturer's instructions. Briefly, the cells were stimulated and then harvested with RIPA lysis buffer. Total protein was isolated from the supernatants, and
$20 \mu \mathrm{g}$ total protein was used for the measurement of $\mathrm{NF}-\kappa \mathrm{B}$ activity.

RNA isolation and reverse transcriptase-polymerase chain reaction. The HepG2 cells were exposed to various chemical stimuli, and RNA was extracted with TRIzol reagent (Life Technologies, Glasgow, UK), according to the manufacturer's instructions. cDNA was synthesized and used as a template for polymerase chain reaction (PCR) amplification. The PCR products were separated on $1 \%$ agarose gels and stained with ethidium bromide.

Western blot analysis. The cells were lysed with lysis buffer [50 mM Tris-HCl, 1\% Triton X-100, 0.5\% sodium deoxycholate, $150 \mathrm{mM} \mathrm{NaCl}, 1 \mathrm{mM}$ EDTA, $1 \mathrm{mM}$ phenylmethylsulfonyl fluoride (PMSF), $1 \mathrm{mM}$ sodium orthovanadate, $1 \mathrm{mM} \mathrm{NaF}$ and $0.2 \%$ protease inhibitor cocktail ( $\mathrm{pH} 7.2$ )]. After separation by sodium dodecyl sulfate (SDS) gel electrophoresis, the proteins were transferred onto a nitrocellulose membrane. Western blot analysis was performed with specific antibodies.

Hoechst staining. After treatment, the cells were fixed with $3.5 \%$ formaldehyde in PBS for $15 \mathrm{~min}$ at room temperature; subsequently, they were washed twice with PBS and stained with $10 \mu \mathrm{M}$ Hoechst 33342 for $30 \mathrm{~min}$ at room temperature. Cleaved nuclei were observed with a fluoromicroscope (Olympus Optical, Tokyo, Japan).

Measurement of ROS. The cells were seeded on 12-well plates with cover slips and were then exposed to stimuli. After stimulation, the cells were fixed with $3.5 \%$ formaldehyde in PBS for $15 \mathrm{~min}$, washed twice with PBS, and stained with $10 \mu \mathrm{M}$ DCFH dye at $10 \mu \mathrm{M}$ for $30 \mathrm{~min}$ at room temperature. Green fluorescence was detected using a fluoromicroscope.

Tumor xenograft model. Five-week-old male nude mice were purchased from Chungang Animal Laboratory (Seoul, Korea). The mice were randomly segregated into 2 groups. HepG2 cells $\left(1 \times 10^{6}\right.$ cells per $\left.100 \mu \mathrm{l}\right)$ were subcutaneously injected into the left flanks of the mice. After 2 weeks, the mice were intraperitoneally (i.p.) injected with luteolin at a dosage of $10 \mu \mathrm{g} / \mathrm{kg}$ every 2 days for 3 weeks. All animal procedures were approved by the Institutional Animal Care and Use Committee of the Korea Food Research Institute.

Statistical analysis. All data are presented as the mean (SD). $\mathrm{P}<0.05$ was indicative of statistical significance. Statistical analyses were performed using SPSS 9.0 (SPSS Inc., Chicago, IL).

\section{Results}

Luteolin-activated AMPK modulates survival gene expression in HepG2 cells. The results of our previous study and those of other studies suggest that the inhibition of cancer cell proliferation by various flavonoids is accompanied by AMPK activation $(20,21)$. We, therefore, investigated the involvement of AMPK in the response to luteolin. We measured the phosphorylation status of AMPK and its substrate ACC. Luteolin 
A

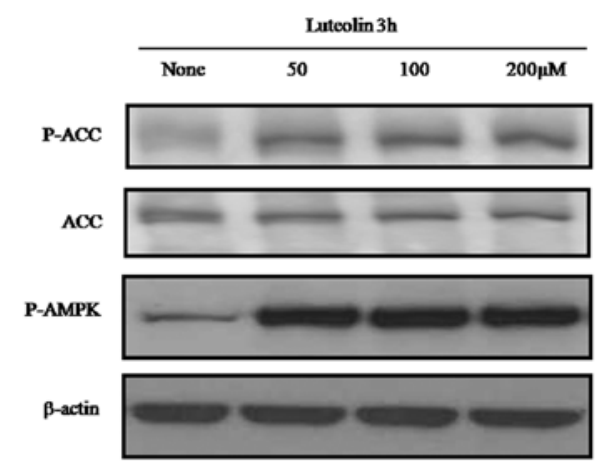

B

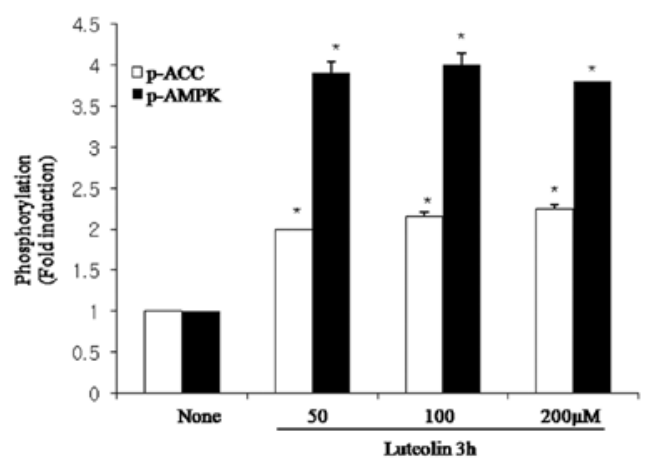

C

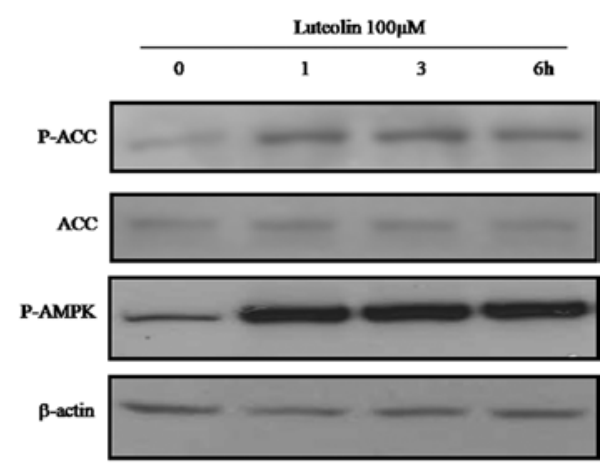

D

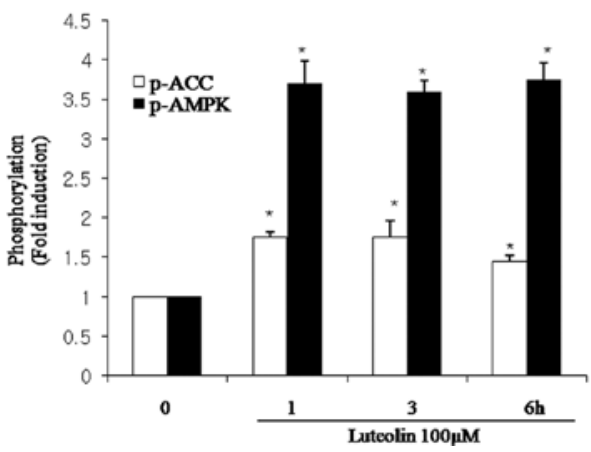

E

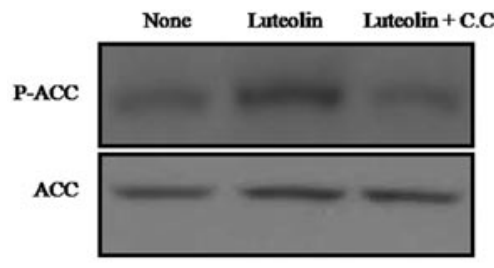

$\mathbf{F}$

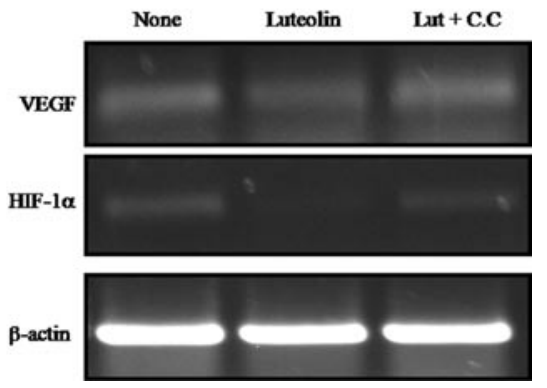

Figure 1. Activation of AMPK by luteolin modulates survival gene expression in HepG2 cells. HepG2 cells were exposed to luteolin in a dose- (A and B) or time-dependent (C and D) manner, and AMPK activation was measured by Western blot analysis with phospho-specific antibodies against AMPK or ACC, a specific downstream target of AMPK ["P<0.05; mean (SD); n=3). (E) HepG2 cells were pre-treated with $10 \mu$ M Compound C (C.C) for 30 min and exposed to $100 \mu \mathrm{M}$ luteolin for $3 \mathrm{~h}$. AMPK activity was measured by Western blot analysis with phospho-specific antibodies. (F) After pre-treatment with $10 \mu \mathrm{M} \mathrm{C.C} \mathrm{for}$ $30 \mathrm{~min}$, the cells were exposed to $100 \mu \mathrm{M}$ luteolin for $6 \mathrm{~h}$. Gene expression was assessed by reverse transcription-polymerase chain reaction. Each experiment was replicated at least 3 times, and DMSO was used as a solvent control (none).

increased AMPK phosphorylation and ACC concentration in a time-dependent manner (Fig. 1A-D). We also tested the effect of AMPK inhibition by Compound $\mathrm{C}$ on the expression of cancer survival genes such as vascular endothelial growth factor (VEGF) and hypoxia-inducible transcription factor (HIF)-1 $\alpha$ in HepG2 cells and found that luteolin markedly inhibited the expression of these genes. Inhibition of AMPK by Compound $\mathrm{C}$ restored survival gene expression (Fig. 1E and $\mathrm{F}$ ). These results suggest that luteolin is an effective activator of the AMPK signaling pathway and plays an important role in HepG2 cell death.

Luteolin effectively induces cell death in vitro and in vivo. We next examined the effects of luteolin on HepG2 viability. Exposure to luteolin significantly blocked cancer cell growth in a dose-dependent manner (Fig. 2A). Under the same conditions, exposure to luteolin induced DNA cleavage
(Fig. 2B). Luteolin thus effectively inhibited cancer growth under these conditions. To confirm the inhibitory effect of luteolin on cancer cell growth, a HepG2 xenograft model was used to examine the anti-tumor properties of luteolin. Mice were treated with luteolin for 3 weeks, and the tumors were separated from the left flanks and weighed. The tumor growth in mice treated with luteolin was dramatically lower than that in the untreated controls and cell culture (Fig. 2C). Under the same conditions, luteolin did not cause a reduction in body weight. Collectively, our data show that luteolin is effective for the inhibition of tumor cell growth.

AMPK activation attenuates NF- $\kappa B$ DNA-binding activity stimulated by luteolin. Numerous studies have suggested that the proteins involved in cancer development, such as $\mathrm{NF}-\kappa \mathrm{B}$, are abnormally activated in malignant cancers; therefore, attenuation of $\mathrm{NF}-\kappa \mathrm{B}$ has been suggested as a potential 
A

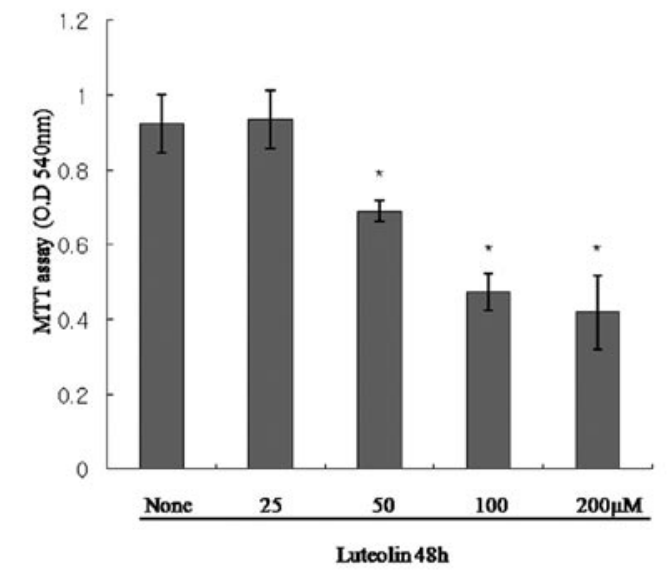

B

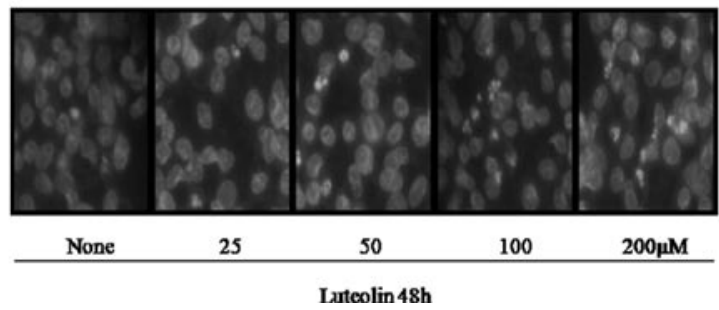

C
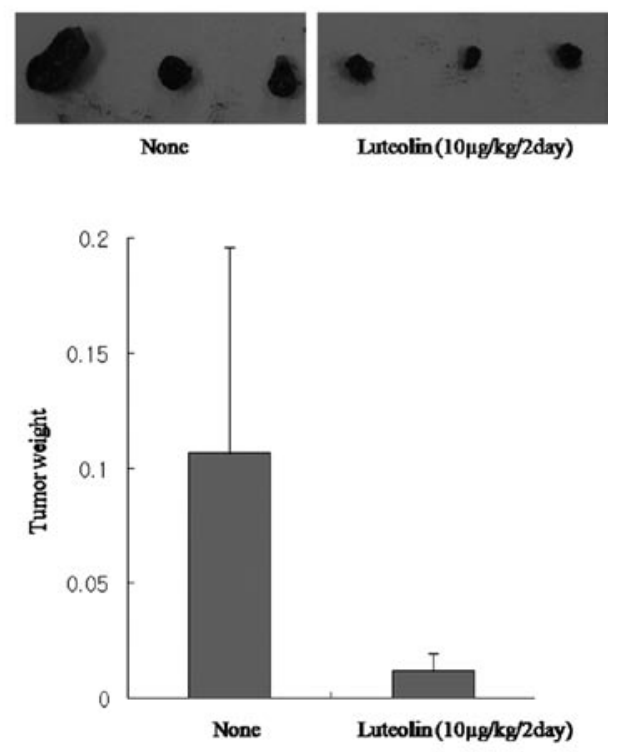

Figure 2. Luteolin exerts anti-tumor properties in HepG2 cells and a mouse tumor xenograft model. (A) HepG2 cells were exposed to various doses of luteolin for $48 \mathrm{~h}$, and relative cell death was measured using the MTT assay. Each experiment was replicated at least 3 times (n=3), and the asterisks indicate a significant difference [ ${ }^{*} \mathrm{P}<0.05$; mean (SD)] versus the untreated sample (DMSO only). (B) Under the same conditions as in A, the morphological features of apoptotic cell death were assessed by Hoechst staining. (C) HepG2 cells (1x10 6 cells per $100 \mu 1)$ were subcutaneously injected into the left flanks of mice (Five mice were assigned to each group). The mice were intraperitoneally (i.p.) injected with luteolin at a dosage of $10 \mu \mathrm{g} / \mathrm{kg}$ every 2 days for 3 weeks. After 3 weeks, the tumor tissue was isolated and weighed. The values in the bar graph are represented as the mean (SD); $n=10$.

method for cancer prevention $(22,23)$. We next investigated whether AMPK activation is critical for the attenuation of $\mathrm{NF}-\kappa \mathrm{B}$ DNA-binding activities. NF- $\kappa \mathrm{B}$ was activated in normally proliferating HepG2 cells (Fig. 3A). Under the same conditions, $\mathrm{NF}-\kappa \mathrm{B}$ activation was reduced by luteolin treatment in a dose-dependent manner. Moreover, our results showed that luteolin inhibited the $\mathrm{NF}-\kappa \mathrm{B}$ activity induced by tumor necrosis factor (TNF)- $\alpha$ treatment (which activates the TNF receptor).

To assess the role of AMPK signaling in luteolin inhibition of NF- $\kappa \mathrm{B}$, the cells were pre-treated with an AMPK inhibitor, Compound $\mathrm{C}$, for $30 \mathrm{~min}$, followed by a $3-\mathrm{h}$ exposure to luteolin. We found that luteolin inhibited NF- $\mathrm{B}$ DNA-binding activity. Under the same conditions, inhibition of AMPK by Compound $\mathrm{C}$ restored NF- $\kappa \mathrm{B}$ activity (Fig. $3 \mathrm{~B}$ ). We confirmed our results by using an adenovirus expressing c-myc-tagged AMPK WT and AMPK DN constructs. Infection with the adenovirus-mediated AMPK DN construct abolished the phosphorylation of ACC, a well-known AMPK substrate (Fig. 3C), and completely restored luteolin inhibition of NF- $\kappa \mathrm{B}$ (Fig. 3D). We also examined the necessity of AMPK activation for $\mathrm{NF}-\kappa \mathrm{B}$ inhibition by using aminoimidazole carboxamide ribonucleotide (AICAR), an AMPK-specific activator. AICAR treatment significantly reduced NF- $\kappa$ B activation (Fig. 3E). Taken together, these results strongly suggest that AMPK activation is critical for the cancer-preventive effects of luteolin via inhibition of $N F-\kappa B$.
ROS are upstream regulators of AMPK induction by luteolin. To identify upstream regulators of AMPK activation by luteolin, we specifically focused on ROS since ROS may act as upstream signaling molecules (24). HepG2 cells were exposed to luteolin for $3 \mathrm{~h}$, in the presence or absence of $\mathrm{N}$-acetyl cysteine (NAC; an ROS scavenger). Subsequently, ROS and NF- $\kappa \mathrm{B}$ activity were measured. Under the conditions used in our study, luteolin caused a dramatic increase in ROS (Fig. 4A) and the phosphorylation of ACC, a direct substrate of AMPK; the phosphorylation of ACC was unexpectedly abolished upon exposure to NAC (Fig. 4B). In addition, treatment with NAC completely restored the NF- $\kappa$ B DNA-binding ability that had been reduced by luteolin treatment (Fig. 4C). These results indicate that the luteolin-stimulated activation of AMPK and suppression of NF- $\mathrm{B}$ DNA binding are both mediated by ROS.

\section{Discussion}

In the present study, we determined that AMPK activity is necessary for NF- $\kappa \mathrm{B}$ inhibition in luteolin-induced HepG2 hepatocarcinoma cell death. We found that AMPK activation by luteolin significantly inhibited NF- $\kappa$ B DNA binding and that this inhibitory effect was mediated by ROS. In addition, AMPK signaling was essential for luteolin inhibition of the expression of cancer survival genes such as VEGF and HIF-1 $\alpha$. Therefore, AMPK activity may be crucial for 
A

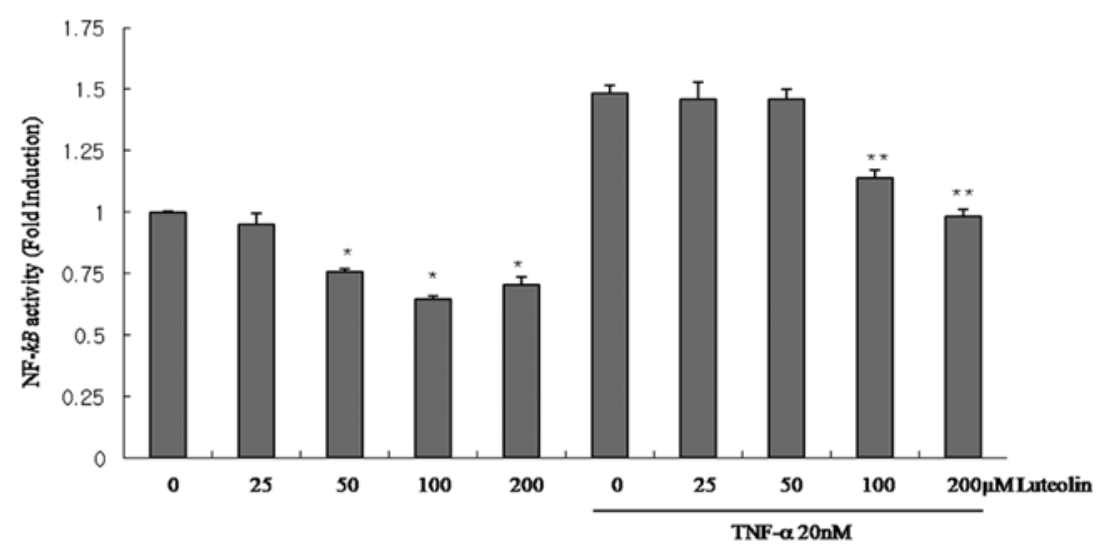

B

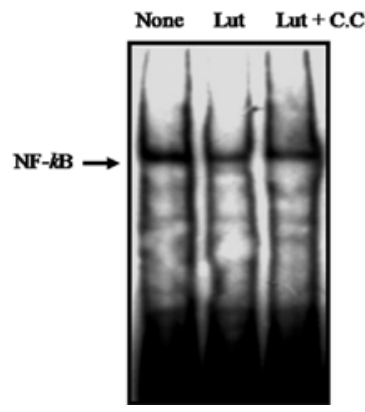

C

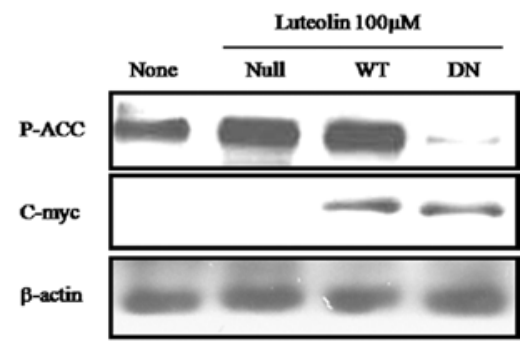

D

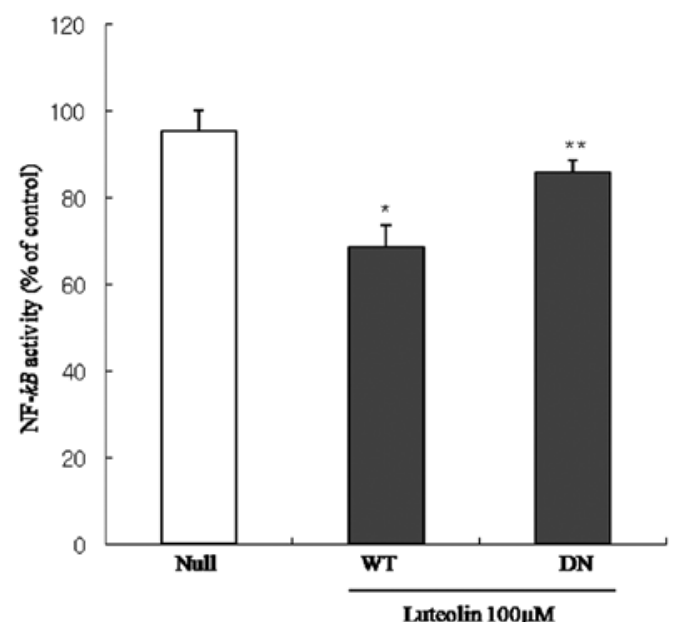

E

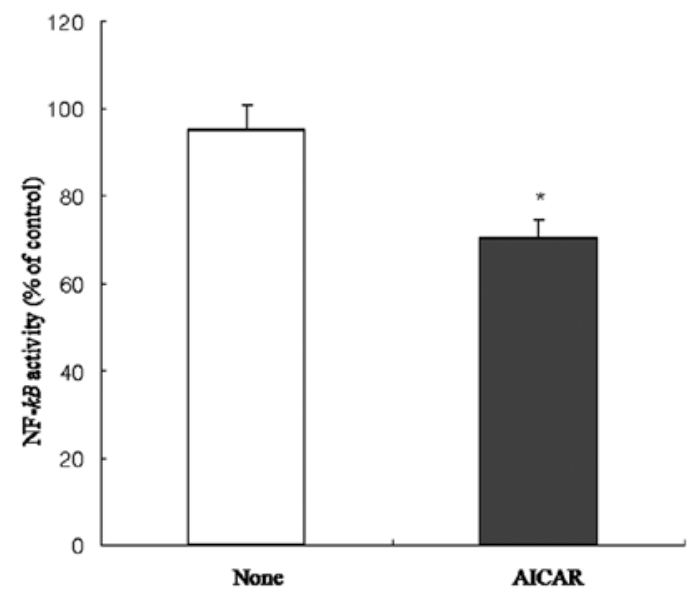

Figure 3. AMPK regulates the NF- $\mathrm{BB}$ signaling pathway upon luteolin treatment. (A) HepG2 cells were treated with luteolin for $6 \mathrm{~h}$ in the presence or absence of TNF- $\alpha$, and NF- $\mathrm{kB}$ activity was measured. "Significant differences were compared with the control $(0)$ at $\mathrm{p}<0.05$. ${ }^{* *}$ Significant differences were compared with the control (0) + TNF- $\alpha$ at $\mathrm{p}<0.05$. (B) Cells were pre-treated with Compound C (C.C) and exposed to $100 \mu$ M luteolin; NF- $\mathrm{BB}$ DNA binding was assessed by EMSA. (C) Cells were infected with the adenovirus expressing c-myc-tagged AMPK-wild-type (WT) and AMPK dominant-negative (DN) constructs. The cells were treated with $100 \mu \mathrm{M}$ luteolin for $3 \mathrm{~h}$, and the expression was assessed by Western blot analysis by using phospho-specific (P)-ACC, a direct AMPK substrate, and c-myc antibodies. (D) After infection with the Ad-AMPK-WT and Ad-AMPK-DN constructs, the cells were directly exposed to $100 \mu \mathrm{M}$ luteolin for $6 \mathrm{~h}$, and NF- $\mathrm{kB}$ activity was measured. ${ }^{*}$ Significant differences were compared with Null, as control at $\mathrm{p}<0.05$. ${ }^{* *}$ Significant differences were compared with WT infection of AMPK at $\mathrm{p}<0.05$. (E) Cells were exposed to $1 \mathrm{mM}$ AICAR for $6 \mathrm{~h}$, and NF-kB activity was measured ["P<0.05; mean $(\mathrm{SD}) ; \mathrm{n}=3]$.

inducing cell death and several cancer cell growth-regulating signals.

Dietary flavonoids exert various anti-cancer, anti-obesity, anti-inflammatory, and anti-diabetic effects, accompanied by either the activation or the inhibition of intracellular signaling pathways $(25,26)$. In cancer cells, dietary flavonoids such as genistein, EGCG and quercetin are thought to prevent cancer development via induction of apoptosis-related signaling proteins or inhibition of cancer proliferation-related proteins $(27,28)$. Luteolin, a natural flavonoid compound, is reported to exert anti-proliferative effects on various types of tumors via several signaling pathways, and several studies have been conducted on the precise regulatory molecules that mediate these effects (5-7). In the present study, we found that luteolin 
A

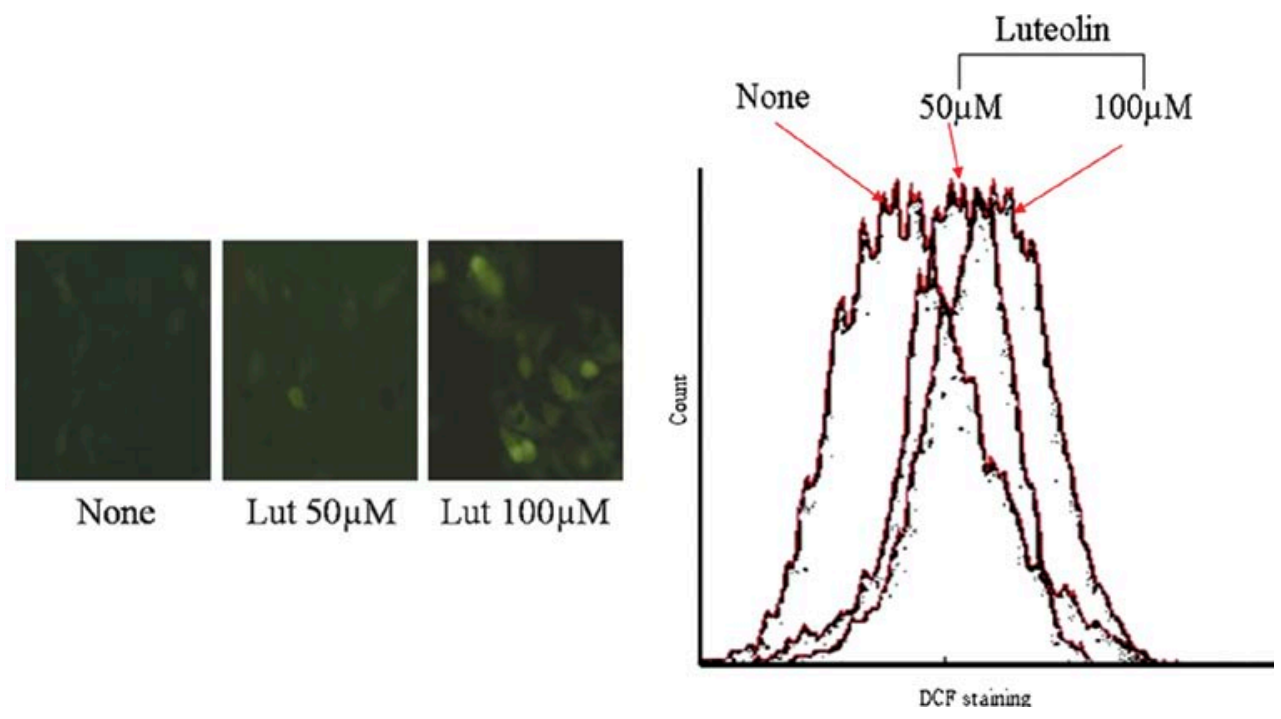

B

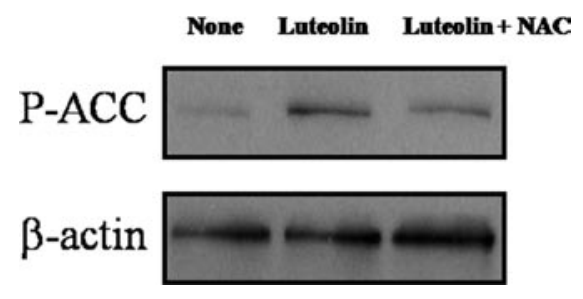

C

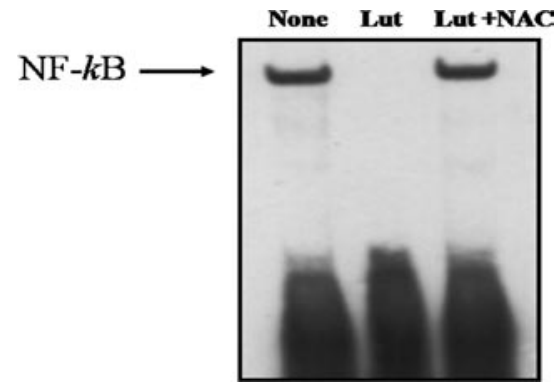

Figure 4. ROS are upstream mediators of AMPK/NF- $\kappa$ B signaling pathways. (A) After stimulation with luteolin, ROS levels were determined with 2',7'-dichlorofluorescein diacetate (DCF) dye. (B) HepG2 cells were exposed to luteolin for $3 \mathrm{~h}$ in the presence or absence of NAC; the cell extracts were subjected to Western blotting with phospho (P)-ACC antibodies. (C) Under the same conditions, total cell extracts were used to assess NF- $\mathrm{kB}$ DNA binding.

exerted its anti-cancer effects by inducing cell death and by suppressing tumor growth in a xenograft model (Fig. 2C). Our data indicated that luteolin strongly inhibited $N F-\kappa B$ activation and DNA binding and that it suppressed HIF-1 $\alpha$ and VEGF expression in HepG2 cells (Figs. 1 and 3). These results suggest that $\mathrm{NF}-\kappa \mathrm{B}$ is a possible target molecule for luteolin-induced cell death as the inhibition of $\mathrm{NF}-\kappa \mathrm{B}$ signaling pathways by various food factors can induce tumor cell apoptosis via inhibition of angiogenesis or metastasisrelated proteins.

Luteolin is reported to inhibit growth and NF- $\kappa \mathrm{B}$ activity in cancer cells $(29,30)$. We found that luteolin inhibited $\mathrm{NF}-\kappa \mathrm{B}$ activity through the regulation of death receptors, and our results revealed that luteolin inhibited the NF- $\kappa \mathrm{B}$ activity induced by TNF- $\alpha$ treatment (which activates the TNF receptor); however, luteolin also suppressed basal $\mathrm{NF}-\kappa \mathrm{B}$ activity in HepG2 cells (Fig. 3A). Luteolin may therefore regulate $\mathrm{NF}-\kappa \mathrm{B}$ signaling through death receptor-dependent or death receptor-independent mechanisms. Next, we examined the possibility that ROS modulate NF- $\kappa \mathrm{B}$ activity via luteolin since ROS are known to be involved in the pathogenesis of a wide variety of human diseases, including cancer, and may contribute to $\mathrm{NF}-\kappa \mathrm{B}$ inhibition (31). It is thought that resveratrol, a dietary polyphenol, inhibits the growth of cancer cells via the inhibition of $\mathrm{NF}-\kappa \mathrm{B}$ and that these inhibitory activities are accompanied by the release of ROS $(32,33)$. We found that ROS were induced by luteolin, which reduced $N F-\kappa B$
DNA-binding activity in HepG2 cells (Fig. 4). On the basis of these results, we propose that it may be possible to tightly regulate both $\mathrm{NF}-\kappa \mathrm{B}$ signaling and ROS activity by treatment with dietary supplements such as flavonoids. Therefore, we tried to identify a novel regulatory protein for $\mathrm{NF}-\kappa \mathrm{B}, \mathrm{ROS}$, and the apoptosis-inducing network.

Several researchers have proposed that AMPK signaling is involved in cancer cell apoptosis stimulated by dietary components $(20,21)$. AMPK, a regulator of cell growth, plays a critical role in the inhibition of proteins involved in proliferation, such as the mammalian target of rapamycin (mTOR), elongation factor 2 and S6 kinase $(34,35)$. It is well known that AMPK activates tumor-suppressor proteins such as tuberous sclerosis complex protein and p53; this supports the hypothesis that AMPK activity may be critical for the suppression of cancer growth $(36,37)$. In the present study, we found that AMPK negatively regulates NF- $\mathrm{B}$ activity and is activated by ROS that are released by luteolin. AMPK is therefore a novel modulating molecule for ROS and NF- $\kappa \mathrm{B}$ signaling, and further studies are required to fully characterize the mechanism underlying the effect of AMPK on NF- $\kappa \mathrm{B}$ regulation and apoptosis-related molecules.

In conclusion, our results revealed that luteolin induces cell death in hepatocarcinoma cells via ROS release and the activation of AMPK signaling pathways, and that AMPK strongly blocked NF- $\kappa \mathrm{B}$ activity to effect its pro-apoptotic properties. Our results suggest that AMPK can be used as 
an effective target molecule for cancer prevention by dietary flavonoids.

\section{Acknowledgements}

This work was supported by research grants from KOSEF for the Biofoods Research Program, Ministry of Education, Science and Technology, and by the Korea Food Research Institute, Korea.

\section{References}

1. Hughes TE: Emerging therapies for metabolic diseases - the focus is on diabetes and obesity. Curr Opin Chem Biol 13: 332-337, 2009.

2. Crozier A, Jaganath IB and Clifford MN: Dietary phenolics: chemistry, bioavailability and effects on health. Nat Prod Rep 26: 1001-1043, 2009.

3. Morisco F, Vitaglione P, Amoruso D, Russo B, Fogliano V and Caporaso N: Foods and liver health. Mol Aspects Med 29: 144-150, 2008.

4. Huntley AL: The health benefits of berry flavonoids for menopausal women: cardiovascular disease, cancer and cognition. Maturitas 63: 297-301, 2009.

5. http://en.wikipedia.org/wiki/Luteolin

6. Xavier CP, Lima CF, Preto A, Seruca R, Fernandes-Ferreira M and Pereira-Wilson C: Luteolin, quercetin and ursolic acid are potent inhibitors of proliferation and inducers of apoptosis in both KRAS and BRAF mutated human colorectal cancer cells. Cancer Lett 281: 162-170, 2009.

7. Jang S, Kelley KW and Johnson RW: Luteolin reduces IL-6 production in microglia by inhibiting JNK phosphorylation and activation of AP-1. Proc Natl Acad Sci USA 105: 7534-7539, 2008.

8. Lee CH, Jeon YT, Kim SH and Song YS: NF-kappaB as a potential molecular target for cancer therapy. Biofactors 29 : 19-35, 2007.

9. Sethi G, Sung B and Aggarwal BB: Nuclear factor-kappaB activation: from bench to bedside. Exp Biol Med 233: 21-31, 2008.

10. Dobrovolskaia MA and Kozlov SV: Inflammation and cancer: when NF-kappaB amalgamates the perilous partnership. Curr Cancer Drug Targets 5: 325-344, 2005.

11. Kabe Y, Ando K, Hirao S, Yoshida M and Handa H: Redox regulation of NF-kappaB activation: distinct redox regulation between the cytoplasm and the nucleus. Antioxid Redox Signal 7: 395-403, 2005.

12. Ahn KS and Aggarwal BB: Transcription factor NF-kappaB: a sensor for smoke and stress signals. Ann NY Acad Sci 1056 : 218-233, 2005

13. Steinberg GR and Kemp BE: AMPK in health and disease. Physiol Rev 89: 1025-1078, 2009.

14. Hardie DG: AMP-activated/SNF1 protein kinases: conserved guardians of cellular energy. Nat Rev Mol Cell Biol 8: 774-785, 2007.

15. Huang CH, Tsai SJ, Wang YJ, Pan MH, Kao JY and Way D: EGCG inhibits protein synthesis, lipogenesis, and cell cycle progression through activation of AMPK in p53-positive and -negative human hepatoma cells. Mol Nutr Food Res 53: $1156-1165,2009$.

16. Hwang JT, Ha J and Park OJ: Combination of 5-fluorouracil and genistein induces apoptosis synergistically in chemo-resistant cancer cells through the modulation of AMPK and COX-2 signaling pathways. Biochem Biophys Res Commun 332: 433-440, 2005

17. Guo D, Hildebrandt IJ, Prins RM, et al: The AMPK agonist AICAR inhibits the growth of EGFRvIII-expressing glioblastomas by inhibiting lipogenesis. Proc Natl Acad Sci USA 106: 12932-12937, 2009.
18. Kim HS, Hwang JT, Yun H, et al: Inhibition of AMP-activated protein kinase sensitizes cancer cells to cisplatin-induced apoptosis via hyper-induction of p53. J Biol Chem 283: 3731-3742, 2008

19. Sung MJ, Kim DH, Jung YJ, et al: Genistein protects the kidney from cisplatin-induced injury. Kidney Int 74: 1538-1547, 2008.

20. Hwang JT, Kwak DW, Lin SK, Kim HM, Kim YM and Park OJ: Resveratrol induces apoptosis in chemoresistant cancer cells via modulation of AMPK signaling pathway. Ann NY Acad Sci 1095: 441-448, 2007.

21. Jung JH, Lee JO, Kim JH, et al: Quercetin suppresses HeLa cell viability via AMPK-induced HSP70 and EGFR down-regulation. J Cell Physiol 223: 408-414, 2010.

22. Wang S, Liu Z, Wang L and Zhang X: NF-kappaB signaling pathway, inflammation and colorectal cancer. Cell Mol Immunol 6: 327-334, 2009.

23. Cortes Sempere M, Rodriguez Fanjul V, Sanchez Perez I and Perona R: The role of the NFkappaB signalling pathway in cancer. Clin Transl Oncol 10: 143-147, 2008.

24. Lamberts RR, Onderwater G, Hamdani N, et al: Reactive oxygen species-induced stimulation of 5'AMP-activated protein kinase mediates sevoflurane-induced cardioprotection. Circulation 120: S10-S15, 2009.

25. Tucker $\mathrm{G}$ and Robards K: Bioactivity and structure of biophenols as mediators of chronic diseases. Crit Rev Food Sci Nutr 48: 929-966, 2008.

26. Larkin T, Price WE and Astheimer L: The key importance of soy isoflavone bioavailability to understanding health benefits. Crit Rev Food Sci Nutr 48: 538-552, 2008.

27. Shenouda NS, Zhou C, Browning JD, Ansell PJ, Sakla MS, Lubahn DB and Macdonald RS: Phytoestrogens in common herbs regulate prostate cancer cell growth in vitro. Nutr Cancer 49: 200-208, 2004

28. Gerhauser C, Klimo K, Heiss E, et al: Mechanism-based in vitro screening of potential cancer chemopreventive agents. Mutat Res 523-524: 163-172, 2003.

29. Horinaka M, Yoshida T, Shiraishi T, et al: Luteolin induces apoptosis via death receptor 5 upregulation in human malignant tumor cells. Oncogene 24: 7180-7189, 2005.

30. Murtaza I, Adhami VM, Hafeez BB, Saleem M and Mukhtar H Fisetin, a natural flavonoid, targets chemoresistant human pancreatic cancer AsPC-1 cells through DR3-mediated inhibition of NF-kappaB. Int J Cancer 125: 2465-2473, 2009.

31. Deeb D, Gao X, Jiang H, et al: Oleanane triterpenoid CDDO-Me inhibits growth and induces apoptosis in prostate cancer cells through a ROS-dependent mechanism. Biochem Pharmacol 79: 350-360, 2010.

32. Madan E, Prasad S, Roy P, George J and Shukla Y: Regulation of apoptosis by resveratrol through JAK/STAT and mitochondriamediated pathway in human epidermoid carcinoma A431 cells. Biochem Biophys Res Commun 377: 1232-1237, 2008.

33. Roy P, Madan E, Kalra N, et al: Resveratrol enhances ultraviolet $\mathrm{B}$-induced cell death through nuclear factor-kappaB pathway in human epidermoid carcinoma A431 cells. Biochem Biophys Res Commun 384: 215-220, 2009.

34. Thomson DM, Fick CA and Gordon SE: AMPK activation attenuates S6K1, 4E-BP1, and eEF2 signaling responses to highfrequency electrically stimulated skeletal muscle contractions. J Appl Physiol 104: 625-632, 2008.

35. Horman S, Browne G, Krause U, et al: Activation of AMP-activated protein kinase leads to the phosphorylation of elongation factor 2 and an inhibition of protein synthesis. Curr Biol 12: 1419-1423, 2002.

36. Feng Z, Hu W, de Stanchina E, Teresky AK, Jin S, Lowe S and Levine AJ: The regulation of AMPK beta1, TSC2, and PTEN expression by p53: stress, cell and tissue specificity, and the role of these gene products in modulating the IGF-1-AKT-mTOR pathways. Cancer Res 67: 3043-3053, 2007.

37. Shaw RJ, Bardeesy N, Manning BD, Lopez L, Kosmatka M, Deepinho RA and Cantley LC: The LKB1 tumor suppressor negatively regulates mTOR signaling. Cancer Cell 6: 91-99, 2004. 